\title{
Process Optimization Potassium Nanofertilizer Production via Ionotropic Pre-gelation using Alginate-Chitosan Carrier
}

\author{
Princess Jenine $\mathrm{Nido}^{1, *}$, Veronica Migo ${ }^{1}$, Monet Concepcion Maguyon-Detras ${ }^{1}$, and Catalino Alfafara ${ }^{1}$ \\ ${ }^{1}$ Department of Chemical Engineering, College of Engineering and Agro-Industrial Technology, University of the Philippines Los \\ Baños, College, Los Baños 4031, Philippines
}

\begin{abstract}
Potassium nanofertilizer synthesis by incorporating potassium in alginate-chitosan carrier via ionotropic pre-gelation was optimized to maximize potassium content and develop controlled release fertilizer. Utilizing two-level factorial design, potassium to alginate ratio, calcium chloride to alginate ratio, and pre-gelation time were determined significant. Central Composite Design for optimization was utilized to generate a Response Surface model relating the factors to the response for numerical optimization. Optimum process conditions for maximum potassium content were (1) 1.5:1 (w/w) potassium to alginate ratio, (2) $6.5: 117.5(\mathrm{v} / \mathrm{v})$ calcium chloride to alginate ratio, and (3) 40 minutes pre-gelation time. The potassium content of the fertilizer formulated at optimum condition was successfully verified to contain $29.75 \% \mathrm{~K}(\mathrm{w} / \mathrm{w})$. Characterization showed that potassium was successfully incorporated in the alginatechitosan carrier as shown by the SEM surface images. DLS result showed two peaks at particle sizes near $594.1 \mathrm{~nm}$ and $102.8 \mathrm{~nm}$ indicating that potassium nanofertilizer was successfully synthesized. Potassium nanofertilizer may be a controlled release fertilizer since only $14.6 \% \mathrm{~K}$ was released after 24 hours in Britton-Robinson buffer solution. Preliminary costing shows higher cost of production based on raw materials, but it may be offset in the long run by longer availability of nutrient and low fertilizer application rate.
\end{abstract}

\section{Introduction}

Fertilizer application is considered as the most effective measure in increasing crop yield to meet the increasing food demand for the growing population [1]. However, excessive and inefficient use of conventional fertilizer for the past years resulting to losses of $40-70 \%$ of nitrogen, $10-90 \%$ of phosphorous, and $50-70 \%$ of potassium led to certain environmental problems [2]. To address this problem, controlled release fertilizers (CRF) may be substituted to conventional fertilizer. Nanofertilizers are CRF that contain nutrient needed by plant incorporated within nanoscale carriers. With the drastic change and modification of chemical and physical properties of material at nanoscale, controlled release property of nanofertilizer is attributed to stability of the nutrient-carrier complex due to high surface tension and stronger intermolecular interaction that prevents immediate dissolution of the fertilizer after soil application [3].

In this study, potassium nanofertilizers, which contain potassium incorporated in an organic carrier alginate-chitosan nanoparticle, was formulated. Potassium is one of the three common plant macronutrients supplied by fertilizers. It serves as an activator for more than 60 enzymatic reactions, aids in ATP synthesis in plants, and maintains over-all plant well-being by controlling the stomatal activities of plants to regulate water and gas exchange [4]. Alginate and chitosan are polysaccharides widely used to synthesize nanocarriers for controlled release material because they are nontoxic, biocompatible, biodegradable, inexpensive, bioabsorbable and bactericidal $[2,5,6]$. Commonly only used for drug delivery systems, this study is one of the first to explore the potential application of alginate and chitosan as nanocarriers for controlled release fertilizer application

The general objective of this study was to optimize the synthesis potassium nanofertilizer with maximum potassium content and with controlled release property by incorporating the optimum amount of potassium ion in alginate-chitosan nanoparticle through ionotropic pregelation method.

\section{Material and Methods}

\subsection{Materials and Reagents}

For the $1.26 \mathrm{mg} / \mathrm{mL}$ alginate stock solution (ALG), white fine powder sodium alginate (RICOGEL GU 9121), purchased from Marine Resources Development Corporation, was dissolved in distilled water and its $\mathrm{pH}$ was adjusted to 4.9 with $1 \mathrm{M}$ hydrochloric acid $(\mathrm{HCl})$.

The $0.10 \mathrm{mg} / \mathrm{mL}$ chitosan stock solution (CHI) was prepared by dissolving yellowish chitosan powder $(15 \%$

*Corresponding author: panido@up.edu.ph | jeninenido@gmail.com 
deacetylation and viscosity of $50 \mathrm{mpa} . \mathrm{s}$ ), purchased from Xi'an Liphar Biotech Co., Ltd., in $1 \%$ acetic acid and its $\mathrm{pH}$ was adjusted to 4.6 through the addition of $1 \mathrm{M}$ sodium hydroxide $(\mathrm{NaOH})$.

For the $36 \mathrm{mM}$ calcium chloride $\left(\mathrm{CaCl}_{2}\right)$ stock solution with $\mathrm{pH} 7$, analytical grade white crystalline calcium chloride dihydrate $\left(\mathrm{CaCl}_{2}-2 \mathrm{H}_{2} \mathrm{O}\right)$, obtained from Merck, was dissolved in distilled water and its $\mathrm{pH}$ was adjusted to 7.0 using $0.1 \mathrm{M} \mathrm{HCl}$ and $0.1 \mathrm{M} \mathrm{NaOH}$.

For the potassium $(\mathrm{K})$ source of the formulated fertilizer, fertilizer-grade muriate of potash (MOP) (0-0$60 \% \mathrm{~K}_{2} \mathrm{O}$ ), was purchased from Amigo Planters.

\subsection{Experimental Design}

Two-level factorial design ( $2^{\mathrm{k}}$ factorial) is a statistical design that uses two levels (low and high) for every factor considered in the experiment to determine its significance to the response [7]. For this experiment, the effect of potassium to alginate ratio (K/ALG), calcium chloride to alginate ratio ( $\mathrm{Ca} / \mathrm{ALG})$, and pre-gelation time ( $\mathrm{PG}$ time) on the $\% \mathrm{~K}$ of the formulated fertilizer was determined through $2^{\mathrm{k}}$ factorial design generated by Design Expert ${ }^{\circledR}$ (Version 11.0.0, Stat-Ease, Inc.). The levels of each process condition utilized in the experiment is shown in Table 1.

Table 1. Levels of process conditions for $2^{\mathrm{k}}$ factorial.

\begin{tabular}{|c|c|c|}
\hline Factor/Process condition & Low level & High level \\
\hline $\mathrm{K} / \mathrm{ALG}(\mathrm{w} / \mathrm{w})$ & $0.5: 1$ & $1.5: 1$ \\
\hline $\mathrm{Ca} / \mathrm{ALG}(\mathrm{v} / \mathrm{v})$ & $6.5: 117.5$ & $1.5: 117.5$ \\
\hline $\mathrm{PG}$ time (minutes) & 40 & 10 \\
\hline
\end{tabular}

Potassium content data was analyzed statistically through Analysis of Variance (ANOVA) and the significant effects of the factors on the responses was determined at $p$-value $<0.5$. Fitness of the data was evaluated by correlation coefficient $\left(\mathrm{R}^{2}\right)$. Assumption of ANOVA was validated using diagnostic plots of Design Expert ${ }^{\circledR}$.

For the optimization part, Response Surface Methodology (RSM) Central Composite Design (CCD) was used. Central Composite Design (CCD) utilized the response from $2 \mathrm{k}$ factorial design added with center points and axial points to account for possible maximum or minimum value [7]. From the significant factors determined by $2^{\mathrm{k}}$ factorial, CCD matrix was generated by Design Expert巴 11 applying two blocks.

From the response surface model generated from CCD, optimum condition for maximizing the potassium content $\left(\% \mathrm{~K}_{\max }\right)$ of the formulated fertilizer. Fertilizer formulated at optimum conditions was experimentally verified and characterized.

\subsection{Fertilizer Formulation}

Potassium nanofertilizer was prepared on a four-step process that included the preparation of potassiumalginate solution (K-ALG), pre-gelation, stabilization, and equilibration. For the preparation of K-ALG, 117.5
$\mathrm{mL}$ of ALG was mixed with MOP and sonicated in Elma Model S $60 \mathrm{H}$ Elmasonic sonicator for 20 minutes at room temperature. On pre-gelation step, $\mathrm{CaCl} 2$ was added dropwise to K-ALG to form pre-gel while sonicating at $37 \mathrm{kHz}$ at RT. On stabilization step, $25 \mathrm{~mL}$ of CHI was added dropwise to stabilize K-ALG while stirring at $600 \mathrm{rpm}$ for 90 minutes at RT. The K-ALG$\mathrm{CHI}$ mixture was stirred for another 30 minutes for better homogenization. Then, the K-ALG-CHI was allowed to stand for 24 hours at room temperature to complete the chemical reaction. After that, the pinkish viscous solution was oven-dried at $70^{\circ} \mathrm{C}$ for 1 hours to obtain solid formulated fertilizer.

\subsection{Potassium Content Determination}

Potassium content $(\% \mathrm{~K})$ of the formulated fertilizer was determined by Sherwood Model 410 Flame Photometer. For this, $0.05 \mathrm{~g}$ sample was subjected to dry ashing method that involves ashing at $550{ }^{\circ} \mathrm{C}$ in a muffle furnace, and treatment with nitric acid $\left(\mathrm{HNO}_{3}\right)$ and $\mathrm{HCl}$.

\subsection{Characterization of the Formulated Fertilizer}

\subsubsection{Scanning Electron Microscope (SEM) Analysis}

The surface morphology and shape of the formulated fertilizer were determined through Hitachi Model SU3500 Scanning Electron Microscope. Sample preparation was done by attaching a small amount of formulated fertilizer on a carbon-coated tape, pressing it to flatten the sample, and placing it on the sample stage.

\subsubsection{Energy Dispersive X-ray Spectroscopy (EDS) Analysis}

Elemental composition of the formulated fertilizer was determined using an EDS detector attached to the SEM used for surface morphology determination.

\subsubsection{Dynamic Light Scattering (DLS) Analysis}

The particle size (PS), particle size distribution (PSD), and polydispersity index (PDI) were determined by Zeta Potential Analyzer Model Zetasizer Nano ZS90 at $25^{\circ} \mathrm{C}$. For this, solid formulated fertilizer was suspended in distilled water and sonicated for 15 minutes as sample preparation.

\subsubsection{Fourier Transform Infrared Spectrometer (FT- IR) Analysis}

The functional groups present in the formulated fertilizer and the alginate-chitosan carrier were analyzed using a Fourier Transform Infrared Spectrometer. FT-IR spectra were analyzed using SpectraGryph ${ }^{\circledR}$ software and KnowItAll® Informatics System software. 


\subsubsection{Solubility Analysis}

The solubility of the formulated fertilizer and the alginate-chitosan carrier were tested on five different solvents namely distilled water, $10 \% \mathrm{NaOH}, 10 \% \mathrm{HCl}$, $10 \%$ ethanol, and $5 \% \mathrm{NaHCO}_{3} .0 .02 \mathrm{~g}$ samples were added with $5 \mathrm{~mL}$ of solvents, mixed, allowed to stand, and observed.

\subsection{6 $\mathrm{pH}$ Analysis}

The $\mathrm{pH}$ of separate clay loam soil slurries with different treatments: (1) formulated fertilizer $+\mathrm{H}_{2} \mathrm{O}$, (2) MOP + $\mathrm{H}_{2} \mathrm{O}$, (3) $\mathrm{H}_{2} \mathrm{O}$, was measured using Horiba Laqua $\mathrm{PH}$ 1100 .

\subsection{Nutrient Release Determination}

The nutrient release of the formulated fertilizer on Britton-Robinson buffer at $\mathrm{pH} 5.41$ and ionic strength 0.0551 (clay loam condition simulation) was determined. Mixed with one liter of the buffer, three separate treatments were done: (1) $0.33 \mathrm{~g}$ formulated fertilizer, (2) $0.25 \mathrm{~g}$ MOP, and (3) blank. $5 \mathrm{~mL}$ of the mixture was pipetted at sampling time (hours): 0, 2, 4, 12, 24, and 41. $\% \mathrm{~K}$ of sample was determined by flame photometer.

\section{Results and Discussion}

\subsection{Effect of Process Conditions}

From $2^{\mathrm{k}}$ factorial design matrix, considering the high and low level of process conditions, the $\% \mathrm{~K}$ of the formulated fertilizer ranged from $1.1 \%$ to $21.6 \%$. The coded equation fitted to the $2^{\mathrm{k}}$ factorial data was presented as follows:

$\% \mathrm{~K}=13.4+4.11 A-1.42 B-0.41 C-1.11 A B+$ $0.17 B C$

where $A=\mathrm{K} / \mathrm{ALG}, B=\mathrm{Ca} / \mathrm{ALG}$, and $C=\mathrm{PG}$ time. Validity of Eq. 1 was confirmed by the insignificant lack of fit p-value, valid ANOVA (p-value=0.05) assumptions based on diagnostic plots, and postANOVA statistics (coefficient of determination $\mathrm{R}^{2}$, adjusted $\mathrm{R}^{2}$, and predicted $\mathrm{R}^{2}$ ).

From this, significant factor $(p$-value $<0.0001)$ $\mathrm{K} / \mathrm{ALG}$ showed the most dominant positive effect on $\% \mathrm{~K}$. Contributing to $\mathrm{K}$ availability, increasing $\mathrm{K} / \mathrm{ALG}$ directly increases the probability of $\mathrm{K}$ ion to form ionic bonds with the free carboxyl groups of the guluronic $(G)$ and mannuronic $(\mathrm{M})$ residues of alginate $[5,6,8]$.

$\mathrm{Ca} / \mathrm{ALG}$ was also found to be a significant factor (pvalue $=0.0003$ ) to $\% \mathrm{~K}$. $\mathrm{Ca} / \mathrm{ALG}$ has a negative effect on $\% \mathrm{~K}$ due to the competition between $\mathrm{K}$ ion and $\mathrm{Ca}$ ion for $\mathrm{G}$ residue binding site of alginate $[5,8]$. Due to this competition, interaction effect $A B$ was also found to be significant. Interaction happens when the level of one factor affects the effect of another factor on the response [1]. At high level of $\mathrm{Ca} / \mathrm{ALG}$, increasing $\mathrm{K} / \mathrm{ALG}$ does not result to a significant increase in $\% \mathrm{~K}$ due to presence of more $\mathrm{Ca}$ competing for the $\mathrm{G}$ residue.

Main factor PG time was statistically insignificant to $\% \mathrm{~K}$ ( $\mathrm{p}$-value $=0.1552$ ). However, $\mathrm{PG}$ time was included in the model due hierarchical principle as interaction effect $B C$ is significant ( $p$-value $=0.0082$ ). Longer PG time resulting to excessive ultrasonic waves may generate enough energy to break the K-ALG ionic bond [9].

\subsection{Optimum Conditions for Fertilizer Formulation}

For optimization, all three factors were considered (K/ALG and Ca/ALG due to statistical significance, and $\mathrm{PG}$ time due to hierarchical principles). From CCD design matrix, data required an inverse transformation to have reduced quadratic model with forward regression reduction. Assuring the validity of the statistical analysis, the coded equation fitted to the CCD data was presented as follows:

$1 / \% \mathrm{~K}=0.06-0.03 A+0.003 B+0.002 C+$
$0.004 A B-0.004 B C+0.01 A^{2}+0.002 B^{2}$

where $A=\mathrm{K} / \mathrm{ALG}, B=\mathrm{Ca} / \mathrm{ALG}$, and $C=\mathrm{PG}$ time. Eq. 2 supports the main factor and interaction effect from $2^{\mathrm{k}}$ factorial. Moreover, the significance of quadratic effects $A^{2}$ and $B^{2}$ indicates desirability of the model in finding minimum or maximum $\% \mathrm{~K}$ value represented in Figure 1.

At low PG time, possible location desired response of maximum $\% \mathrm{~K}$ is indicated by the red area in Figure 1. Using Design Expert ${ }^{\circledR} 11$, optimum conditions for maximum $\% \mathrm{~K}$ was determined and experimentally validated, with average percentage difference of $3.54 \%$, as shown in Table 2 with average $\% \mathrm{~K}_{\max }$ of $29.75 \%$.

Table 2. Optimum conditions for maximum $\% \mathrm{~K}$.

\begin{tabular}{|c|c|}
\hline Factor/Process condition & Optimum value \\
\hline $\mathrm{K} / \mathrm{ALG}(\mathrm{w} / \mathrm{w})$ & $1.5: 1$ \\
\hline $\mathrm{Ca} / \mathrm{ALG}(\mathrm{v} / \mathrm{v})$ & $6.5: 117.5$ \\
\hline $\mathrm{PG}$ time $($ minutes $)$ & 40 \\
\hline
\end{tabular}

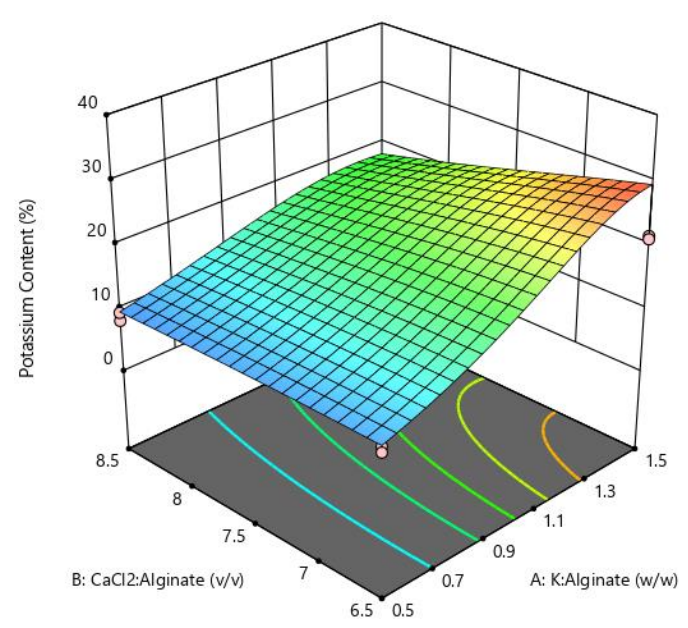

Fig 1. Response surface model for $\% \mathrm{~K}$. 


\subsection{Characteristics of the Formulated Fertilizer at Optimum Conditions}

\subsubsection{Morphology}

Shown in Figure 2, SEM image shows the surface of the formulated fertilizer with darker fibrous material embedded with defined white crystals.

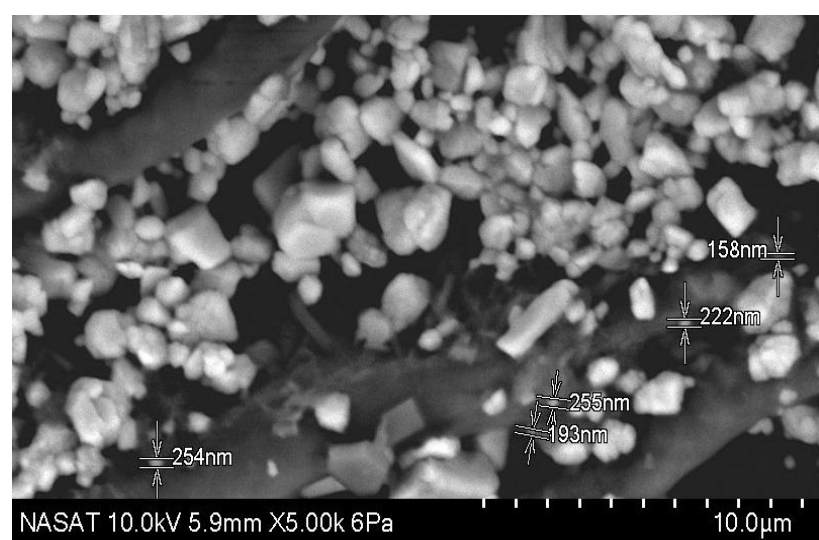

Fig 2. SEM surface image of formulated K fertilizer.

The darker fibrous or planar sheets appearance of ALG-CHI carrier is formed during air drying as the ALG-CHI polymer backbone collapses after moisture evaporates leaving compacted planar stacks of polymer [6]. White crystals are assumed to be $\mathrm{K}$ and $\mathrm{Ca}$ ions embedded in ALG-CHI may be due to electrostatic interaction. Uneven sizes and distribution of these crystals on ALG-CHI may be due to agglomeration of particles during synthesis and drying [5,6]. Rough estimate of crystal particle size based on Figure 2 shows smallest particle size of $151 \mathrm{~nm}$.

The surface morphology and shape of the formulated fertilizer were determined through Hitachi Model SU3500 Scanning Electron Microscope. Sample preparation was done by attaching a small amount of formulated fertilizer on a carbon-coated tape, pressing it to flatten the sample, and placing it on the sample stage.

\subsubsection{Energy Dispersive $X$-ray Spectroscopy (EDS) Analysis}

Elemental composition analysis, shown in Figure 3, shows six major elements present in the formulated fertilizer namely chlorine, potassium, carbon, oxygen, indium, and sodium. Results shows that formulated fertilizer does not contains elements toxic to plant growth [4].

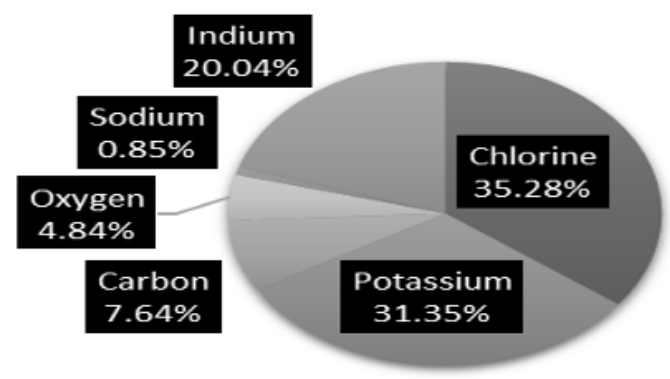

Figure 3. Elemental composition of formulated $\mathrm{K}$ fertilizer.

\subsubsection{Particle Size Distribution (PSD)}

DLS result indicated non-homogeneous PSD with polydipersity index (PDI) of 0.931 as shown on two distinct peaks in the PSD of the fertilizer formulated at optimum condition. The higher peak is at $594.1 \mathrm{~nm}$ with an intensity of $90.1 \%$, while the lower peak is at 102.1 $\mathrm{nm}$ with intensity $9.9 \%$. Larger particle size is probably due to agglomeration of molecules and absorption of water due to the swelling property of ALG-CHI [5]. On the other hand, both peaks on the PSD at $594.1 \mathrm{~nm}$ and $102.1 \mathrm{~nm}$ fall within the acceptable range of polymerbased nanoparticle size of $10 \mathrm{~nm}$ to $1000 \mathrm{~nm}$ indicating nanofertilizer formation [2].

\subsubsection{Functional Groups}

Confirming ALG-CHI complex formation, FT-IR spectra, shown in Figure 4, showed slight shift in the characteristic absorption peaks of ALG at $1613 \mathrm{~cm}^{-1}$ ($\mathrm{CO}$ ) and $1417 \mathrm{~cm}^{-1}$ (-COOH) to $1557 \mathrm{~cm}^{-1}$ and $1407 \mathrm{~cm}^{-}$ ${ }^{1}$, respectively; and chitosan at $1646 \mathrm{~cm}^{-1}$ (amide) and $1601 \mathrm{~cm}^{-1}$ (-NH) to $1557 \mathrm{~cm}^{-1}$ and $1407 \mathrm{~cm}^{-1}$ [8].

On the other hand, $\mathrm{K}$ and $\mathrm{Ca}$ incorporation in ALG$\mathrm{CHI}$ was confirmed by the shift in characteristic peak of the formulated fertilizer compared to ALG-CHI as shown in Figure 4. The FT-IR spectra show shift in the absorbance peak from $1613 \mathrm{~cm}^{-1}$ (-CO) and $1417 \mathrm{~cm}^{-1}$ ($\mathrm{COOH})$ to $1560 \mathrm{~cm}^{-1}$ and $1410 \mathrm{~cm}^{-1}$, respectively, indicating $\mathrm{Ca}$ were bonded to the $\mathrm{G}$ residue of ALG pregel facilitating the incorporation of $\mathrm{K}$ to produce potassium nanofertilizer [8].

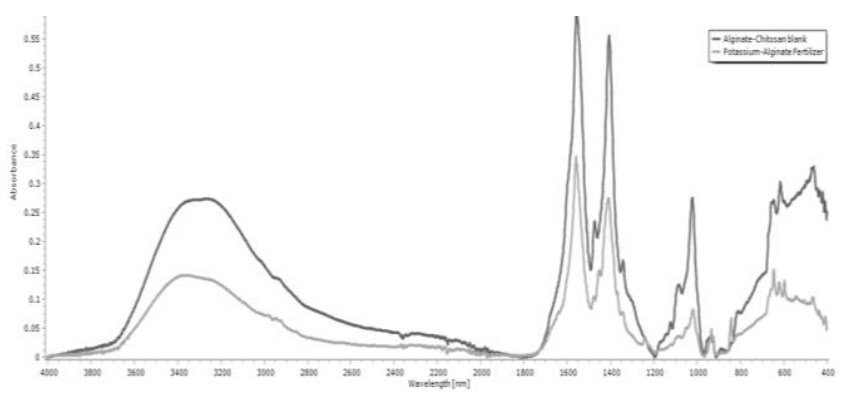

Fig 4. FT-IR spectra of formulated K fertilizer and ALG-CHI. 


\subsubsection{Solubility}

Solubility results indicate that ALG-CHI and formulated fertilizer exhibit the same behavior in different solvent, where both are soluble only in $5 \%$ sodium bicarbonate which contains ions that weakens Ca-ALG interaction. Both are insoluble in $10 \%$ ethanol, $10 \% \mathrm{HCl}, 10 \%$ $\mathrm{NaOH}$, and distilled water. Extremely low solubility in highly acidic and highly basic condition, which are exhibited by $10 \% \mathrm{HCl}$ and $10 \% \mathrm{NaOH}$, respectively, is due to nanostructure agglomeration at $\mathrm{pH}$ below 3.5 and above 1.5 that prevents dissolution. Low solubility in water indicates the formulated fertilizer potential for controlled release property [2].

\subsubsection{Effect on Soil $\mathrm{pH}$}

$\mathrm{pH}$ analysis shows that the soil $\mathrm{pH}$ loaded with MOP became slightly more acidic as the $\mathrm{pH}$ became 6.45 from 6.72. On the other hand, application of the formulated fertilizer resulted also to a slightly more acidic soil with $\mathrm{pH}$ 6.17. In terms of its effect on plants, the soil $\mathrm{pH}$ change to 6.17 due to the application of formulated fertilizer is still within the range of the optimum $\mathrm{pH}$ for crop production of $\mathrm{pH} 5.0$ to 7.0. In the long run, accumulation of less soluble ALG-CHI becomes minimal and causes insignificant effect on soil condition due to its biodegradability [4].

\subsection{Nutrient Release Characteristic}

Shown in Figure 5, release profile of $\mathrm{K}$ from MOP exhibits fast release property since $36 \%(>15 \%)$ of the K it contains was released after 24 hours. For the formulated fertilizer, about $14.6 \%$ of the nutrient was released after 24 hours, satisfying one of the criteria for controlled release fertilizer (CRF) based on the European Standardization Committee [3]. Potential CRF is due to the nutrient release mechanism of ALG-CHI being polymer relaxation and Fickian diffusion resulting to Case II transport of material $[5,8]$.

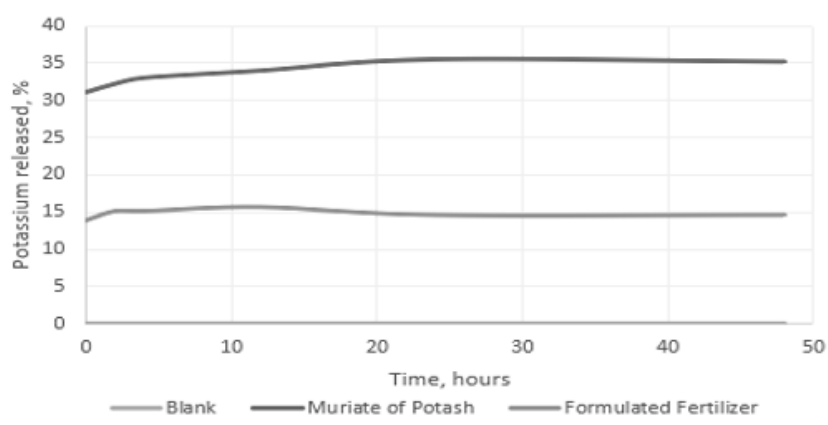

Fig 5. Nutrient release profile of formulated fertilizer \& MOP.

\subsection{Preliminary Cost}

Considering conservative estimates of wholesale prices of raw materials used to synthesized K-nanofertilizer at optimum condition, one unit of formulated fertilizer (Php 150 per $\mathrm{kg}$ ) is about $90 \%$ more expensive that MOP,
But, the low efficiency $(<30 \%)$ of MOP resulting to higher rate of application and shorter availability of nutrient makes potassium nanofertilizer potentially more economical and environmentally sustainable than MOP in the long run.

\section{Conclusion}

Potassium nanofertilizer synthesis was optimized to achieve maximum $\% \mathrm{~K}$. From factorial screening, the process conditions significant in the $\% \mathrm{~K}$ of the formulated fertilizer are $\mathrm{K} / \mathrm{ALG}$ and $\mathrm{Ca} / \mathrm{ALG}$, which have a positive and negative effect, respectively on $\% \mathrm{~K}$.

Optimum conditions were found to be (1) $1.5: 1$ $\mathrm{K} / \mathrm{ALG}$, (2) $6.5: 117.5 \mathrm{Ca} / \mathrm{ALG}$, and (3) PG time of 40 minutes, resulting to formulated fertilizer containing $29.7 \% \mathrm{~K}$.

With particle size distribution peaks at $594.1 \mathrm{~nm}$ and $102.1 \mathrm{~nm}$, potassium nanofertilizer was successfully synthesized. From K release determination, potassium nanofertilizer may be a controlled release fertilizer after $14.6 \% \mathrm{~K}$ was released after 24 hours of fertilizer loading

This research was financially supported by the Department of Science and Technology - Philippine Council for Agriculture, Aquatic, and Natural Resources Research and Development (DOST-PCAARRD).

\section{References}

1. A. R. Rajonee, F. Nigar, S. Ahmed, \& S. I. Huq. Synthesis of nitrogen nano fertilizer and its efficacy. Can. J. Pure Appl. Sci. 10, 3913-3919 (2016)

2. G. K. Wasupalli, \& D. Verma. Molecular interactions in self-assembled nano-structures of chitosan-sodium alginate-based polyelectrolyte complexes. Int. J. Bio. Macro. 114, 10-17 (2011)

3. S. I. Sempeho, H. T. Kim, E. Mubofu, \& A. Hilonga. Meticulous overview on the controlled release fertilizers. Adv. Chem. (2014).

4. P. Barak. Essential elements for plant growth

5. M. A. Azevedo, A. I. Bourbon, A. A. Vicente, \& M.A. Cerqueira. Alginate/chitosan nanoparticles for encapsulation and controlled release of vitamin B2. Int. J. Bio. Macro. 71, 141-146 (2014)

6. G. Conzatti, D. Faucon, M. Castel, F. Ayadi, S. Cavalie, \& A. Tourrette. Alginate/chitosan polyelectrolyte complexes: A comparative study of the influence of the drying step on physicochemical properties. Carb. Polym. 172, 142-151 (2017)

7. M. J. Anderson, \& P. J. Whitcomb. DOE simplified: Practical tools for effective experimentation. (2007)

8. G. Lim, \& M. S. Ahmad. Development of $\mathrm{Ca}$ alginate-chitosan microcapsules for encapsulation and controlled release of imidacloprid to control dengue outbreaks. J. Ind. Eng. Chem. 56, 312-393 (2017)

9. Y. Feng, G. Kopplin, K. Sato, K. I. Draget, \& K. M. Vårum. Alginate gels with a combination of calcium and chitosan oligomer mixtures as crosslinkers. Carb. Polym. 156, 490-497 (2017) 